Paidéia, 2004, 14(29), 359-369

\title{
TRAÇOS DE PERSONALIDADE DE CRIANÇAS E EMOÇÕES: EVIDÊNCIA DE VALIDADE ${ }^{1}$.
}

\author{
Fermino Fernandes Sisto ${ }^{1}$ \\ Universidade São Francisco
}

\begin{abstract}
Resumo : Este estudo analisou as relações entre traços de personalidade e a autopercepção das emoções de alegria, tristeza, coragem e medo, com vistas a evidências de validades. A Escala de Traços de Personalidade para Crianças e o teste de Autopercepção de Emoções foram aplicados, em sala de aula e coletivamente, a 1095 crianças com idades de 8 a 10 anos. Quanto ao traço psicoticismo e neuroticismo as hipóteses foram confirmadas. Para o primeiro foram encontradas correlações positivas para as emoções coragem e tristeza, e negativas para alegria; e para o segundo, a maior parte de seus coeficientes significativos estavam relacionados ao medo e tristeza. Em relação ao traço de extroversão foram confirmadas as expectativas de correlações positivas com alegria e coragem, e negativas com tristeza, mas houve exceções. Finalmente, em relação ao traço sociabilidade confirmou-se parcialmente a hipótese, pois para os meninos não houve correlação significativa com as emoções avaliadas.
\end{abstract}

Palavras-chave: traços de personalidade; emoções; evidências de validade.

\section{CHILDREN'S PERSONALITY TRAITS AND EMOTIONS: EVIDENCE OF VALIDITY}

\begin{abstract}
The present study analyzed the relationships among personality traits and self-perception of the emotions related to happiness, sadness, courage and fear to gather evidences of validity. The Escala de Traços de Personalidade para Crianças (Personality Traits Scale for Children) and the Autopercepção de Emoções (Self- Perception of Emotion Test) were collectively applied on 1095 children aged 8 to 10 years old, in their own classroom. Regarding to psychoticism and neuroticism traits, the hypotheses were confirmed. For the first one positive correlations were found for courage and sadness, and negative correlations for happiness; for the last one the major part of the significant coefficients were related to fear and sadness. Concerning extroversion trait the expectation of positive correlation with happiness and courage and negative correlation with sadness were confirmed, although there were exceptions. Finally, about sociability trait, the hypothesis was partially confirmed, since there were no significant correlations between boys and the evaluated emotions.
\end{abstract}

Key-words: personality traits; emotions; evidences of validity.

Os traços de personalidade podem ser concebidos como subjacentes ao que é característico da conduta. Seriam tendências ou modos de se comportar em uma diversidade de situações. Adjetivos como honesto, digno de confiança, ansioso, excitável, dominador, impulsivo, agitado, irascível, impetuoso, impaciente e amigável descrevem tendências que podem dominar os traços de personalidade (Sisto, no prelo).
A problemática envolvida na consistência e congruência da conduta humana refere-se a determinados comportamentos que voltam a se apresentar, com certa freqüência, ao longo da vida. Nesse sentido, é possível defender que uma certa consistência da conduta caracteriza as pessoas, e pode se falar em traços de personalidade como característica psicológica (Eysenck \& Eysenck, 1987).

\footnotetext{
${ }^{1}$ Artigo recebido para publicação em 10/05/2004; aceito em 27/10/2004.

${ }^{1}$ Endereço para correspondência: Fermino Fernandes Sisto, Rua Carlos Guimarães, 150, Ap. 82, Campinas, SP, 13024-200, Email: fsisto@nipnet.com.br
} 


\section{Fermino Fernandes Sisto}

Traços de personalidade representariam tendências relativamente estáveis na forma de pensar, sentir e atuar com as pessoas. Por sua vez, emoção pode ser entendida como a tendência de um organismo a aproximar-se ou afastar-se de um objeto, acompanhada de alterações somáticas, refletindo o estado pessoal e sua relação ao objeto (Marino Júnior, 1975). De acordo com Fiamenghi Junior (2001) seria mais interessante usar o termo "processo emocional" para se referir ao que ocorre no indivíduo quando ele vive uma emoção. Argumenta que esse termo imprime a idéia do movimento, do dinamismo interno produzido por essa função psicológica. Nesse contexto, este estudo teve a preocupação em analisar as relações entre traços de personalidade e a autopercepção das emoções de alegria, tristeza, coragem e medo. Na realidade, entende-se que as emoções façam parte dos traços de personalidade, ainda que por si sós não possam explicá-los. Assim, é possível buscar evidências de validades entre esses constructos.

A Escala de Traços de Personalidade para Crianças (ETPC) (Sisto, no prelo) está configurada para crianças brasileiras de 5 a 10 anos, sem histórico conhecido de patologia psicológica. O instrumento possui um total de 30 itens, com validade de constructo e de conteúdo para medir quatro fatores, quais sejam, neuroticismo, psicoticismo, extroversão e sociabilidade.

Os estudos de precisão forneceram bons indicadores. A consistência interna forneceu para o psicoticismo um alfa de 0,91, para extroversão e sociabilidade 0,88 e para neuroticismo 0,80. Pela técnica de duas metades de Spearman-Brown os índices também foram considerados bons, pois se encontrou 0,92 para psicoticismo, 0,87 para extroversão, 0,81 para sociabilidade e 0,79 para neuroticismo. Os coeficientes de correlação de Pearson na situação de teste-reteste também foram altos. Encontrou-se 0,92 para psicoticismo, 0,90 para sociabilidade, 0,84 para neuroticismo e 0,80 para extroversão.

Cinco estudos foram realizados usando o ETPC e, de certa forma, ofereceram algumas evidências de validade do instrumento. Três deles estão relacionados à situação de ensino-aprendizagem e os outros dois a outras características psicológicas que poderiam estar relacionadas a traços de personalidade.

Pacheco e Sisto (2003) estudaram a relação entre traços de personalidade e aprendizagem por conflito sócio-cognitivo em crianças de 5 a 7 anos. A análise indicou que os traços de personalidade psicoticismo e adequação (sociabilidade) foram significativos para explicar o desempenho dos sujeitos quanto à aprendizagem no pós-teste imediato. Por sua vez, Bazi (2003) constatou que conforme aumentou a pontuação em neuroticismo aumentou também a intensidade da dificuldade de aprendizagem nos alunos de segundas séries, enquanto que conforme aumentou o nível de dificuldade de aprendizagem diminuiu a intensidade de extroversão. Ao lado disso, Pacheco (2003) comparou crianças com e sem dificuldade de aprendizagem na escrita e concluiu que extroversão e psicoticismo não foram capazes de discriminar os grupos, mas neuroticismo e sociabilidade discriminaram, de tal modo que as crianças com dificuldade de aprendizagem acentuada apresentaram altas pontuações em neuroticismo e baixas em sociabilidade.

Os outros dois estudos trabalharam em perspectivas diferentes. As relações entre o ETPC e o teste de cores de Lüscher foram estudadas por Sisto, Pacheco, Guerrero, e Urquijo (2001) e os resultados indicaram que as correlações foram positivas e significativas entre psicoticismo e os níveis de ansiedade e tensão; e que houve correlações negativas e significativas com o traço de neuroticismo. Finalmente, Sisto, Bueno e Rueda (2003) investigaram as relações entre traços de personalidade e percepção visomotora, especificamente distorção de formas e integração pelo teste gestáltico de Bender. Com relação às medidas de integração os resultados mostraram que conforme diminuiu a integração, aumentou a intensidade do neuroticismo, como também que a não integração também faz parte do quadro de psicoticismo. Por sua vez, as medidas de distorção do teste apresentaram correlações positivas e significativas apenas com o traço psicoticismo, facilitando a conclusão de que quanto maior e mais vezes foram registradas as distorções, maior foi a intensidade do traço psicoticismo. As análises indicaram também que em grupos extremos os resultados se mantiveram.

Para coletar informações sobre emoções, usouse o Teste de Autopercepção de Emoções (Sisto \& Bazi, 1999). É um instrumento para estudantes brasileiros de 8 a 14 anos, com validade de constructo e validade de conteúdo para medir quatro fatores, quais 
sejam, alegria, tristeza, coragem e medo. Os estudos de precisão forneceram indicadores que podem ser considerados bons. A consistência interna por alfa de Cronbach forneceu para a subescala de medo um índice de 0,78 , para a subescala de coragem o índice foi de 0,82 , para a subescala de alegria encontrou-se um alfa igual a 0,75 e, finalmente, para a subescala de tristeza o índice foi de 0,83.

A alegria foi definida, para a construção da subescala, como uma forma de prazer que se relaciona à euforia e à busca de contato. Por sua vez, a tristeza seria uma forma de desprazer aliada à retirada de qualquer desejo e sua manifestação característica é estar indefeso (Frijda, 1995). Assim, a tristeza possibilitaria o embotamento dos sentimentos, a imobilidade e lentidão dos processos fisiológicos (Marino Júnior, 1975). A alegria, entretanto, implicaria uma atividade consciente que fornece significados e valores (Misrahi, 2001).

Avia e Sánchez (1995) destacam que as experiências precoces com determinadas emoções (alegria, tristeza e decepção, por exemplo) facilitariam a ocorrência de condutas que, se repetidas, podem ser convertidas em traços. Nesse sentindo, argumenta, uma pessoa feliz e satisfeita teria mais condições de se buscar ambientes que satisfaçam mais suas necessidades, retro-alimente suas emoções, ao mesmo tempo em que lhe permita alcançar seus objetivos. Defende, também, que o afeto positivo, deve ser multideterminado por influências situacionais e temperamentais.

A tristeza, diferentemente da depressão, se refere ao sentimento de esgotamento que se segue à perda ou à mágoa (Viscott, 1982). Em termos genéricos, se uma pessoa consegue avaliar o que a deixou triste, de forma objetiva, é possível afirmar que está triste e não depressiva; se fica triste por um longo tempo e perde o vínculo com a causa da tristeza está perdido, freqüentemente, o resultado é a depressão. A tristeza é diluída pelo viver o dia a dia, caracterizando-se muito mais como uma fase passageira no fluxo natural dos sentimentos, enquanto que a tristeza na depressão intensifica-se e é uma ruptura no fluxo dos sentimentos (Verztman, 1995).

É necessário esclarecer que, no instrumento usado, a alegria e tristeza foram abordadas como emoções não-patológicas, ou seja, “naturais”. A tristeza foi operacionalizada como algo que paralisa a ação, existindo a crença de que toda ação é um erro, e como um sentimento constante, estando a pessoa acompanhada ou sozinha. Por sua vez, a alegria foi avaliada quando presente em pessoas divertidas, animadas em situações novas, que auxiliam os outros e sentindo-se bem mesmo quando só.

O medo, no geral, paralisa e pode ser observado em uma mescla de expressões evitantes, auto-protetoras (Frijda, 1995). O medo seria um tipo de proteção automática do corpo. Para Baker (2000), a patologia começaria a existir quando o medo transforma-se em pânico, em uma experiência terrível, e os sentimentos são muito fortes e sem uma razão óbvia. Há uma ligação com os acontecimentos da vida, mas é “invisível”.

Há uma diferença entre o medo e a ansiedade talvez necessária de ser explicitada. Rodrigues (1976) defende que o medo e a ansiedade são formas de defesa do organismo contra a ameaça do perigo; entretanto, há medo sempre que uma ameaça concreta está presente, enquanto que na ansiedade o estado emocional é motivado por antecipação de futura ameaça. Ao lado disso, a coragem pode vencer o medo, e, é indicativo de coragem apenas a tentativa de enfrentá-lo (Comte-Sponville,1995). May (1975) defende que a coragem não é o oposto do desespero, mas a capacidade de continuar, apesar do desespero. Assim, coragem seria a disposição e energias necessárias para superar o medo e não sua ausência.

A principal característica da coragem é se originar no interior do eu e envolver a possibilidade de sacrifício, muitas vezes inevitável, de peculiaridades da pessoa. Para Comte-Sponville (1995), enquanto a covardia é desprezada, a coragem talvez seja universalmente admirada. Informa também que cada civilização tem seus medos, mas o que não varia, ou varia muito pouco, é a coragem para superar o medo. Apesar de um aspecto da personalidade altamente valorizado, não se pode esquecer que é ambivalente, em termos morais e éticos, pois ela existe tanto para o bem quanto para o mal.

O instrumento utilizado operacionalizou a emoção de medo em relação à solidão, ao desconhecido, ao escuro, e à altura, incluindo também medo de multidão, de lugares fechados e de fenômenos naturais. A coragem, por sua vez, foi operacionalizada em relação a situações desafiadoras, englobando o sentimento de medo. 


\section{Fermino Fernandes Sisto}

Com base no pressuposto de que as emoções fazem parte do constructo traços de personalidade, procurou-se levantar hipóteses dessas relações, para cada traço, com base nas características definidas no manual do ETPC.

No que se refere ao traço de personalidade psicoticismo, aventou-se que seriam encontradas correlações significativas e positivas para as emoções coragem e tristeza, e correlações significativas e negativas para alegria. Os elementos que possibilitaram essa expectativa se referem ao fato de que a pessoa com alta pontuação nesse traço tende a ser dura, deprecia o perigo, é solitária e cria problemas com os outros, tem tendência a ser cruel e desumana, mostrando-se hostil, inclusive com os mais íntimos, apresenta poucos indicativos de socialização, assim como de sentimentos de empatia e culpabilidade. Por sua vez, uma baixa pontuação em psicoticismo indica que a pessoa tem sensibilidade afetiva, é preocupada com os outros e é convencional.

Com relação ao traço de personalidade neuroticismo, esperam-se correlações significativas e positivas com medo e tristeza. Isso se deve a que entre os componentes do neuroticismo estão ansiedade, depressão, sentimento de culpa, baixa auto-estima, timidez, melancolia, tristeza, temor, nervosismo, inquietação, emotividade, isso é, mostra uma forte instabilidade emocional. O neuroticismo está associado à incapacidade de persistir em face de obstáculos. Por sua vez, uma baixa pontuação em neuroticismo indicaria pessoas pouco impulsivas, que recuperam com facilidade o autocontrole.

Assim, espera-se que haja correlação positiva e significativa do traço de personalidade extroversão com alegria e coragem, mas negativa com tristeza. Essa expectativa se deve a que a pessoa, com alta pontuação nesse traço, pode ser descrita como impulsiva, despreocupada, em busca de sensações, otimista, assertiva, vivaz, ativa e animada, espontânea e aberta às relações interpessoais; arrisca-se freqüentemente, adora mudança, é otimista, dogmática, tem muitos amigos, e não gosta de ler ou estudar sozinha. Contrariamente, um sujeito com baixa pontuação em extroversão é tranqüilo, retraído, introspectivo e reservado, de poucos amigos, reflete antes de agir, desconfia dos impulsos, não gosta de se divertir; sua vida é ordenada, controla cuidadosamente seus sentimentos, é um pouco pessimista; São sujeitos tímidos e solitários.

Por fim, em relação ao traço de personalidade sociabilidade espera-se correlações significativas e negativas com coragem, pois a escala informa sobre a tendência a comportar-se dentro de regras e conveniências sociais e não possui indicadores suficientes para uma interpretação em termos de condutas anti-sociais. No entanto, uma baixa pontuação indicaria que a pessoa se mostra como é realmente, apresenta certa independência frente às normas sociais ou condutas socialmente aceitas e pode ser indicativo de condutas que merecem ser observadas e avaliadas mais detalhadamente, pois podem estar relacionadas a condutas anti-sociais.

\section{Método}

\section{Participantes}

Participaram do estudo 1095 crianças que freqüentavam de segunda à quarta séries, com idades variando em 8 e 10 anos (média=9,04 e desvio padrão=0,77). Do total de crianças, 50,1\% eram do sexo masculino e 49,9\% do sexo feminino; 27,8\% tinham 8 anos, 40,2\% tinham 9 anos e com 10 anos, 32\%.

\section{Instrumentos}

Traços de Personalidade: A avaliação foi realizada por meio da Escala de Traços de Personalidade para Crianças, um questionário com 30 itens, (Sisto, no prelo), com precisão e validade de constructo para os seguintes fatores: neuroticismo, psicoticismo, extroversão e sociabilidade. É um instrumento para ser usado em crianças de 5 a 10 anos de idade. Na escala de neuroticismo, a pessoa é avaliada por 7 itens; na de extroversão, 10 itens; na de psicoticismo, 11 itens; e na de sociabilidade, 6 itens. É composta por perguntas e a criança deve responder sim ou não a cada uma delas. Os itens estão distribuídos ao acaso e o gabarito permite separá-los e pontuar os traços.

Emoções: A avaliação das emoções foi feita, realizada por meio da Autopercepção de Emoções, um instrumento com 32 itens, (Sisto \& Bazi, 1999), com precisão e validade de constructo para os seguintes fatores: alegria, tristeza, medo e coragem. É 
um instrumento para ser usado em pessoas de 8 a 14 anos de idade. Todas as quatro subescalas contêm 8 itens, que são afirmações para as quais a pessoa deve responder sim ou não a cada uma delas. As afirmações estão distribuídas ao acaso e o gabarito permite separá-las e pontuar as quatro emoções.

\section{Procedimentos}

Os instrumentos foram aplicados coletivamente, em sala de aula, por uma equipe distribuída com dois aplicadores por sala de aula, um para dar as instruções, e outro para auxiliar os sujeitos individualmente caso fosse necessário. Para a Escala de Per- sonalidade Infantil cada criança possuía o instrumento com os itens e as alternativas (sim-não) e o aplicador lia cada item e esperava que as crianças anotassem sua resposta, fazendo um $\mathrm{x}$ na alternativa escolhida, após um breve treinamento para tal.

\section{Resultados}

As diferentes idades forneceram condutas em intensidades semelhantes em relação às emoções avaliadas, pois em nenhuma situação estudada as diferenças das médias foram significativas estatisticamente (Tabela 1). Mesmo resultado foi observado em relação aos traços psicoticismo e extroversão.

Tabela 1: Média, desvio padrão e valores de $F$ e $p$ para as subescalas de emoções em relação às idades

\begin{tabular}{|c|c|c|c|c|c|c|c|c|c|}
\hline & \multicolumn{2}{|c|}{8 anos } & \multicolumn{2}{|c|}{9 anos } & \multicolumn{2}{|c|}{10 anos } & \multirow[b]{2}{*}{ df } & \multirow[b]{2}{*}{ F } & \multirow[b]{2}{*}{ p } \\
\hline & média & $d p$ & média & $\mathbf{d p}$ & média & $\mathrm{dp}$ & & & \\
\hline Medo & 12,91 & 2,3 & 12,69 & 2,08 & 12,67 & 2,07 & 2 & 1,188 & 0,305 \\
\hline Coragem & 11,01 & 2,14 & 11,09 & 2,14 & 11,16 & 2,10 & 2 & 0,375 & 0,688 \\
\hline Tristeza & 13,88 & 1,99 & 13,57 & 1,98 & 13,74 & 1,89 & 2 & 2,163 & 0,115 \\
\hline Alegria & 9,29 & 1,69 & 9,15 & 1,32 & 9,04 & 1,27 & 2 & 2,365 & 0,094 \\
\hline Psicoti & 9,23 & 1,94 & 9,40 & 1,80 & 9,11 & 1,97 & 2 & 2,126 & 0,120 \\
\hline Extroversão & 1,62 & 1,71 & 1,54 & 1,55 & 1,57 & 1,55 & 2 & 0,200 & 0,819 \\
\hline Neuroticismo & 3,89 & 1,79 & 3,51 & 1,83 & 3,24 & 1,87 & 2 & 9,724 & 0,000 \\
\hline Sociabilidade & 1,92 & 1,65 & 2,10 & 1,68 & 2,63 & 1,77 & 2 & 15,627 & 0,000 \\
\hline
\end{tabular}

No entanto, em relação aos traços de personalidade neuroticismo e sociabilidade as diferenças foram significativas. Os dados indicaram que para o traço neuroticismo, as médias diminuíram conforme aumentaram as idades, e para o traço sociabilidade as médias aumentaram conforme aumentaram as idades.

Por sua vez, exceção feita à medida de alegria, todas as outras medidas forneceram informações de que as médias entre os diferentes sexos não podem ser atribuídas ao acaso. No caso das medidas de psicoticismo e coragem as meninas apresentaram uma média maior que os meninos, enquanto que nas demais medidas, os meninos forneceram dados que indicaram maiores médias que as meninas (Tabela 2).

Tabela 2: Valores de $t$ e $p$ para as subescalas de emoções em relação aos gêneros.

\begin{tabular}{|l|r|r|}
\hline & \multicolumn{1}{|c|}{ t } & P \\
\hline Psicoticismo & $-7,758$ & 0,000 \\
\hline Extroversão & 1,980 & 0,048 \\
\hline Neuroticismo & 6,209 & 0,000 \\
\hline Sociabilidade & 4,387 & 0,000 \\
\hline \multicolumn{3}{|l}{} \\
\hline Medo & 10,804 & 0,000 \\
\hline Coragem & $-14,599$ & 0,000 \\
\hline Tristeza & 5,506 & 0,000 \\
\hline Alegria &, 938 & 0,348 \\
\hline
\end{tabular}




\section{Fermino Fernandes Sisto}

Para estudar as associações entre os traços de personalidade e as emoções avaliadas, primeiramente foram calculados os coeficientes de correlação de Pearson entre essas variáveis, considerando os gêneros separada e conjuntamente. Depois foram calculadas as associações entre essas variáveis por idade e gênero. Os dados serão apresentados por traço de personalidade e emoções. Assim, a Tabela 3 apresenta os coeficientes de correlação em relação ao traço de personalidade psicoticismo e as emoções.

Tabela 3: Coeficientes de Correlação de Pearson entre as medidas de psicoticismo e emoções, por gênero e independentemente de idades, e por idades e gênero.

\begin{tabular}{|c|c|c|c|c|c|}
\hline Idade & gênero & Medo & Coragem & Tristeza & A legria \\
\hline & masculino & 0,077 & $0,155^{* *}$ & $0,192 * *$ & $-0,103^{*}$ \\
\hline & feminino & 0,067 & $0,127 * *$ & $0,294 * *$ & $-0,237 * *$ \\
\hline & geral & 0,013 & $0,229 * *$ & $0,189 * *$ & $-0,152 * *$ \\
\hline \multirow[t]{2}{*}{8 anos } & masculino & 0,096 & $0,178^{*}$ & $0,294 * *$ & $-0,180^{*}$ \\
\hline & feminino & $-0,079$ & $0,182^{*}$ & $0,231 * *$ & $-0,308^{* *}$ \\
\hline \multirow[t]{2}{*}{9 anos } & masculino & 0,109 & $0,147^{*}$ & $0,161^{*}$ & $-0,074$ \\
\hline & feminino & 0,112 & $0,161 *$ & $0,289^{* *}$ & $-0,090$ \\
\hline \multirow[t]{2}{*}{10 anos } & masculino & 0,035 & $0,162^{*}$ & $0,160^{*}$ & $-0,082$ \\
\hline & feminino & 0,133 & 0,053 & $0,366 * *$ & $-0,345^{* *}$ \\
\hline
\end{tabular}

Em relação ao traço psicoticismo apenas a emoção medo não mostrou qualquer associação significativa para nenhuma das situações estudadas. Coragem e tristeza forneceram índices significativos e positivos, indicando que conforme aumentou a pontuação em psicoticismo aumentaram também as pontuações nas emoções coragem e tristeza, exceção feita às meninas de 10 anos em relação à coragem. Em relação à alegria, com exceção para as crianças de 9 anos e os meninos de 10 anos, as correlações foram negativas e significativas, sugerindo que a pontuação em alegria diminuiu conforme aumentou a pontuação em psicoticismo. No geral pode-se inferir que a maior ou menor intensidade do traço psicoticismo está associada, respectivamente, à maior ou menor intensidade de coragem e tristeza; que a percepção da intensidade da alegria pode ser inversamente proporcional à intensidade do psicoticismo; e que eles podem ou não sentir medo, independentemente da intensidade desse traço de personalidade.

Tabela 4: Coeficientes de Correlação de Pearson entre as medidas de neuroticismo e emoções, por gênero e independentemente de idades, e por idades e gênero.

\begin{tabular}{|c|c|c|c|c|c|}
\hline Idade & gênero & medo & coragem & tristeza & alegria \\
\hline & Masculino & $0,267 * *$ & 0,068 & $0,285^{* *}$ & 0,009 \\
\hline \multirow[t]{2}{*}{ Neuroticismo } & Feminino & $0,256 * *$ & $-0,060$ & $0,361 * *$ & $-0,099^{*}$ \\
\hline & geral & $0,303 * *$ & $-0,080^{*}$ & $0,347 * *$ & $-0,031$ \\
\hline \multirow[t]{2}{*}{8 anos } & masculino & $0,263^{* *}$ & 0,107 & 0,149 & 0,164 \\
\hline & feminino & $0,329 * *$ & 0,000 & $0,297 * *$ & $-0,042$ \\
\hline \multirow[t]{2}{*}{9 anos } & masculino & $0,335^{* *}$ & 0,077 & $0,333^{* *}$ & $-0,082$ \\
\hline & feminino & $0,247^{* *}$ & $-0,092$ & $0,375^{* *}$ & $-0,162^{*}$ \\
\hline \multirow[t]{2}{*}{10 anos } & masculino & $0,169^{*}$ & 0,052 & $0,340 * *$ & $-0,068$ \\
\hline & feminino & $0,193 *$ & $-0,082$ & $0,405 * *$ & $-0,114$ \\
\hline
\end{tabular}

** Correlação significativa ao nível de 0.01

* Correlação significativa ao nível de 0.05 . 
O traço de personalidade neuroticismo (Tabela 4), independentemente da idade, apresentou a maior parte de seus coeficientes significativos relacionados ao medo e tristeza, sugerindo que conforme aumentou a pontuação em neuroticismo aumentou também a pontuação em medo e tristeza. Independentemente do gênero, houve uma correlação negativa com coragem, indicativo de que o aumento em neuroticismo diminui a coragem; como também as meninas forneceram uma correlação negativa com alegria, sugerindo uma relação inversa entre as pontuações dessas duas variáveis. Com esses dados, pôde-se interpretar que o neuroticismo está associado, principalmente, às emoções de medo e tristeza.

Em relação às idades, as correlações e as tendências encontradas se mantiveram, no que concerne às emoções medo e tristeza, exceção feita às crianças de 8 anos do gênero masculino em relação à emoção tristeza. Neuroticismo e alegria apenas as meninas de 9 anos forneceram correlação negativa e significativa, mantendo a tendência já descrita anteriormente.

Por sua vez, em relação ao traço de extroversão, independentemente da idade, as crianças apresentaram coeficientes de correlação positivos mais altos em alegria, principalmente os meninos, conforme pode ser observado na Tabela 5. Esse dado é indicativo de que conforme aumentaram as pontuações de extroversão, aumentaram também as pontuações em alegria. A mesma tendência também pôde ser observada em relação aos meninos no que concerne à emoção coragem; independentemente do gênero a tendência se manteve, ainda que a correlação tenha sido bem mais baixa. Inversamente, conforme diminui a pontuação em neuroticismo aumentou a pontuação em tristeza, conforme sugerem as correlações negativas e significativas encontradas nas três situações estudadas.

Tabela 5: Coeficientes de Correlação de Pearson entre as medidas de extroversão e emoções, por gênero e independentemente de idades, e por idades e gênero.

\begin{tabular}{|c|c|c|c|c|c|}
\hline Idade & gênero & Medo & coragem & tristeza & alegria \\
\hline \multirow{3}{*}{ Extroversão } & masculino & $-0,079$ & $0,160^{* *}$ & $-0,140 * *$ & $0,341 * *$ \\
\hline & feminino & $-0,104^{*}$ & 0,074 & $-0,175^{* *}$ & $0,132^{* *}$ \\
\hline & geral & $-0,063$ & $0,079 *$ & $-0,143^{* *}$ & $0,256^{* *}$ \\
\hline \multirow[t]{2}{*}{8 anos } & masculino & $-0,174^{*}$ & 0,065 & $-0,249 * *$ & $0,232^{* *}$ \\
\hline & feminino & $-0,026$ & $0,184^{*}$ & $-0,092$ & 0,070 \\
\hline \multirow[t]{2}{*}{9 anos } & masculino & $-0,094$ & $0,169^{*}$ & $-0,164^{*}$ & $0,324 * *$ \\
\hline & feminino & $-0,192^{* *}$ & 0,094 & $-0,216^{* *}$ & $0,158^{*}$ \\
\hline \multirow[t]{2}{*}{10 anos } & masculino & 0,037 & $0,233 * *$ & $-0,003$ & $0,474 * *$ \\
\hline & feminino & $-0,084$ & $-0,059$ & $-0,220 * *$ & $0,184^{*}$ \\
\hline
\end{tabular}

A mesma tendência também pôde ser observada, desta feita em relação às meninas no que se refere ao medo. Assim, a intensidade de extroversão tendeu a ser paralela à alegria e inversa em relação à tristeza; e em relação ao medo e coragem os meninos tenderam a apresentar intensidades semelhantes entre coragem e extroversão e as meninas inversas com medo.

Os dados parecem indicar que a interação entre idade e gênero em relação à extroversão e as emoções, produziram efeitos diferentes da correlações observadas independentemente das idades. Assim, as pontuações das meninas de 8 anos não se associaram com extroversão, enquanto que as outras situações mantiveram a mesma tendência. Em relação à tristeza, as pontuações das meninas de 8 anos e dos meninos de 10 anos também não forneceram índices significativos, embora nas outras a tendência tenha se mantido. Por sua vez, enquanto que coragem teve correlações significativas e positivas com os meninos e não com as meninas, os meninos de 8 anos apresentaram uma correlação não significativa e as meninas de 9 anos informaram uma correlação 


\section{Fermino Fernandes Sisto}

significativa. Finalmente, no que concerne ao medo, apenas as meninas de 9 anos e os meninos de 8 anos forneceram correlações negativas e significativas, enquanto que a tendência tinha sido apenas as meninas apresentarem esse tipo de tendência.

Finalmente, o traço de sociabilidade (Tabela 6), independentemente da idade, forneceu correlações significativas e negativas para as meninas em relação às emoções coragem e tristeza, indicativo de que conforme aumentou a pontuação em sociabilidade diminui a pontuação de coragem e de tristeza. A outra correlação significativa foi em relação à coragem e independentemente do gênero, com a mesma tendência já relatada. Os meninos não apresentaram qualquer correlação significativa entre as emoções avaliadas e o traço em questão.

Tabela 6: Coeficientes de Correlação de Pearson entre as medidas de sociabilidade e emoções, por gênero e independentemente de idades, e por idades e gênero.

\begin{tabular}{l|l|r|r|r|r}
\hline Idade & gênero & medo & \multicolumn{1}{c|}{ coragem } & tristeza & alegria \\
\hline \multirow{4}{*}{} & Masculino & $-0,081$ & $-0,087$ & $-0,024$ & $-0,084$ \\
\cline { 2 - 6 } & Feminino & $-0,008$ & $-0,163^{* *}$ & $-0,147^{* *}$ & 0,047 \\
\cline { 2 - 6 } & geral & 0,003 & $-0,174^{* *}$ & $-0,064$ & $-0,023$ \\
\hline
\end{tabular}

\begin{tabular}{l|l|r|r|r|r}
\hline 8 anos & masculino & $-0,015$ & $-0,091$ & $-0,042$ & $-0,137$ \\
\cline { 2 - 6 } & feminino & 0,115 & $-0,213^{*}$ & 0,017 & 0,027 \\
\hline \multirow{3}{*}{ anos } & masculino & $-0,120$ & $-0,101$ & $-0,040$ & $-0,059$ \\
\cline { 2 - 6 } & feminino & $-0,093$ & $-0,196^{* *}$ & $-0,243^{* *}$ & $-0,024$ \\
\hline \multirow{2}{*}{10 anos } & masculino & $-0,088$ & $-0,113$ & 0,017 & $-0,028$ \\
\cline { 2 - 6 } & feminino & 0,002 & $-0,082$ & $-0,194^{*}$ & $0,193^{*}$ \\
\hline
\end{tabular}

** Correlação significativa ao nível de 0.01

* Correlação significativa ao nível de 0.05 .

Considerando as idades, as meninas de 9 e 10 anos conservaram a tendência já descrita em relação à tristeza, e as de 8 e 9 anos em relação à coragem. Uma diferença em relação à tendência encontrada, independentemente da idade, foi que as meninas de 10 anos apresentaram uma correlação significativa e positiva em relação à alegria, indicativo de que conforme aumentou a pontuação em sociabilidade, aumentou também a pontuação em alegria.

\section{Discussão e Conclusão}

A emoção pode ser vista como uma interface entre o organismo e seu meio, como mediadora entre as situações e os eventos constantemente mutáveis e as respostas comportamentais do indivíduo.

Várias são as razões que explicam os poucos estudos referentes às emoções positivas. Os sentimentos negativos atraem mais a atenção, pois são importantes para a sobrevivência, e a satisfação é concebida como um sentimento mais simples, menos interessante, e ainda, a normalidade não é tão estudada, não sendo, assim, tão explicada.

As culturas ensinam os seus membros a expressar certas emoções e suprimir outras, e as provas experimentais demonstram que ao menos certa parte da variedade entre culturas é atribuível às diferenças no tocante às regras de manifestação que governam a expressão de emoção. Assim, para Harris (1996), os membros de diferentes culturas expressam emoções diferentes em público, embora as emoções expressas quando estão sozinhos sejam muito semelhantes. A existência de tais regras de manifestação significa que a emoção verdadeira e a emoção aparente podem não coincidir.

A idade das crianças estudadas não apresentou relação com as medidas feitas, exceção aos traços de personalidade neuroticismo e sociabilidade cujas diferenças foram significativas. Em relação ao neuroticismo houve uma diminuição conforme aumentou a idade das crianças e no caso de sociabilidade as médias aumentaram conforme aumentaram as idades. Esses dados são semelhantes aos descritos nos manuais. 
No que tange ao sexo, exceção feita à medida de alegria, todas as outras medidas forneceram informações de que as médias entre os diferentes sexos não podem ser atribuídas ao acaso. No caso das medidas de psicoticismo e coragem as meninas apresentaram uma média maior que os meninos, enquanto que nas demais medidas, os meninos forneceram dados que indicaram maiores médias que as meninas.

Em relação ao traço psicoticismo aventou-se que seriam encontradas correlações significativas e positivas para as emoções coragem e tristeza, e correlações significativas e negativas para alegria. A hipótese foi confirmada no geral e em quase todas as idades, exceção feita para as meninas de 10 anos em relação à coragem e em relação à alegria para as crianças de 9 anos e os meninos de 10 anos. Pôde-se afirmar, com base nos resultados, que conforme aumentou a pontuação em psicoticismo aumentaram também as pontuações nas emoções coragem e tristeza e que a pontuação em alegria diminuiu conforme aumentou a pontuação em psicoticismo e que eles podem ou não sentir medo, independentemente da intensidade desse traço de personalidade.

Assim, as crianças com altas pontuações em psicoticismo se percebem como pessoas que vencem o medo com facilidade e enfrentam as situações, mas possuem também a tristeza em alta intensidade e alegria, em baixa. De acordo com Avia e Sánchez (1995) a alegria intensifica a confiança e a pessoa tenta formar vínculos sociais, enquanto que a tristeza reduz a sua atividade e a pessoa tenta restaurar a sua energia. Nesse sentindo, essas características reforçam o quadro do traço psicoticismo, que caracteriza a pessoa como dura, solitária, depreciadora do perigo, pouco socializada, hostil até com os mais íntimos, o que implicaria na dificuldade em formar vínculos. De fato, a emoção relacionada positivamente a esse traço, a coragem, é ambivalente em termos morais e éticos, pois as pessoas que a possuem podem utilizá-la para o bem e para o mal.

A hipótese concernente ao traço de personalidade neuroticismo espera correlações significativas e positivas com medo e tristeza, o que foi confirmado, pois a maior parte de seus coeficientes significativos estavam relacionados ao medo e tristeza. Assim, pôde-se constatar que conforme aumentou a pontuação em neuroticismo aumentou também a pon- tuação em medo e tristeza (com exceção dos meninos de 8 anos). Entretanto, observou-se uma correlação negativa com coragem, não previsto inicialmente, indicativo de que o aumento em neuroticismo diminui a coragem; como também as meninas forneceram uma correlação negativa com alegria, ou seja, diminuição dos índices de alegria conforme aumenta os de neuroticismo.

Considerando que o traço de personalidade neuroticismo inclui características tais como a ansiedade, depressão, baixa auto-estima, timidez, melancolia, tristeza, temor e nervosismo, a presença de emoções como medo, tristeza e pouca coragem parecem sugerir uma adequação das características com as emoções percebidas pelas crianças.

A respeito das emoções tidas como negativas, Fiamenghi Junior (2001) defende que as emoções causadas por experiências dolorosas e difíceis, podem aumentar no decurso do tempo (como um efeito de "incubação"). Entretanto, algo diferente pode ocorrer se a pessoa mantiver contato com fontes de emoções tidas como positivas por um longo período de tempo. Nesse caso, a emoção negativa poderá desaparecer lentamente, possibilitando o aparecimento do sentimento de indiferença.

Em se tratando dos traços de personalidade associados a emoções tidas como negativas, a tendência das pessoas é buscarem ambientes adequados e ela e, nesse sentido, buscarem uma retroalimentação para suas condutas e sentimentos.

Por sua vez, em relação ao traço de extroversão, foram confirmadas as expectativas de correlações positivas e significativas com alegria e coragem, mas negativas com tristeza. Assim, conforme aumentaram as pontuações de extroversão, aumentaram também as pontuações em alegria e coragem; e, contrariamente, conforme aumentaram as pontuações de extroversão, diminuiu a pontuação em tristeza. Entretanto, as exceções ficaram por conta das meninas, que para coragem não apresentaram correlação significativa, mas sim para medo, que foi negativa e significativa.

Com relação às idades e sexo, as exceções foram correlação não significativa com alegria nas meninas de 8 anos; com tristeza nas meninas de 8 anos e meninos de 10 anos; com coragem nos meninos de 8 anos e nas meninas de 9 e 10 anos; com 


\section{Fermino Fernandes Sisto}

medo houve correlações não esperadas com meninos de 8 anos e meninas de 9 anos. Assim, esperavase 18 correlações, das quais 6 não foram confirmadas; e não eram esperadas 6 correlações, das quais duas ocorreram.

Esses resultados sugerem que a tendência geral não se constituiu em uma soma de partes iguais, mas que resultados peculiares a cada grupo formado pelas variáveis sexo e idade facilitaram uma tendência geral, nem sempre simétrica às sub partes. Apesar disso, no geral a tendência dos resultados foi confirmar a hipótese aventada.

Aparentemente a autopercepção de alta intensidade de alegria e baixa de tristeza são as duas características mais constantes nas crianças estudadas. Esses dados são bastantes congruentes com o traço de personalidade extroversão que caracteriza pessoas tidas como despreocupadas, otimistas, vivazes, ativas e animadas, espontâneas e abertas às relações interpessoais. Avia e Sánchez (1995) destacam a necessidade e importância de explicar como se funciona a capacidade de experimentar, com freqüência, emoções positivas, pois há muitas indicações que existem diferenças individuais significativas na afetividade (positiva-negativa) das pessoas. Também, defende que as emoções positivas encontram-se entre as mais importantes da personalidade humana, já que relacionadas ao bem-estar geral das pessoas e têm implicações importantes nas relações interpessoais e para o estabelecimento de metas e projetos de vida.

Com relação à coragem, parece ser uma característica autopercebida mais constantemente em meninos de 9 e 10 anos e muito pouco em meninas. Apesar traço de personalidade extroversão não possibilitar essa diferenciação, ela encontra suporte, pois pessoas com esse traço se caracterizam por serem impulsivas, despreocupadas, ativas, assertivas, que se arriscam freqüentemente e adoram a mudança e estão em busca de sensações.

Por último, em relação ao traço de personalidade sociabilidade eram esperadas correlações significativas e negativas com coragem, o que foi parcialmente confirmado, pois os meninos não apresentaram qualquer correlação significativa entre as emoções avaliadas e o traço em questão. No que tange às meninas, as pontuações das emoções coragem e tristeza diminuíram conforme aumentou a pontuação em sociabilidade, sugerindo que quanto mais as meninas seguem as regras e normas sociais as intensidades da coragem e tristeza diminuem.

As exceções ficaram por conta, além dos meninos, das meninas de 8 anos em relação à tristeza, 10 anos em relação à coragem e 10 em relação à alegria, pois a correlação positiva e significativa sugeriu que as pontuações de sociabilidade e alegria aumentaram e diminuíram simetricamente.

Este estudo apresenta alguns limites, principalmente, na possibilidade de explicação de certos achados não previstos pelas definições dos constructos, nem pela literatura da área. Ao lado disso, seria interessante contar com outros indicadores dessas emoções aqui trabalhadas para uma contraposição, como também para uma possibilidade de ampliação das interpretações. Nesse sentido, outras formas de pesquisar as relações entre traços e emoções tornam-se necessário. Provavelmente a maior contribuição deste estudo não esteja nas confirmações parciais de suas hipóteses, mas muito mais nos resultados inesperados que, de certa forma, poderão ser os disparadores de novos estudos.

Por fim, restaria comentar que os estudos sobre a personalidade de crianças são escassos e mais ainda no Brasil. Nesse sentido, seria interessante outras pesquisas que pudessem esclarecer um pouco mais sobre esse assunto, tendo em vista o papel que esse constructo desempenha na vida das pessoas. A busca de relações entre traços de personalidade e outras variáveis tem sido feita no Brasil. Assim, traços de personalidade têm sido estudado em relação à aprendizagem por conflito sócio-cognitivo (Pacheco \& Sisto, 2003); em relação à dificuldade de aprendizagem (Bazi, 2003); comparando crianças com e sem dificuldade de aprendizagem na escrita (Pacheco, 2003); relacionando com o teste de cores de Lüscher (Sisto, Pacheco, Guerrero \& Urquijo, 2001); e com percepção visomotora (Sisto, Bueno \& Rueda, 2003). Esses estudos, apesar de indicaram um começo e abrirem alternativas para outras pesquisas, sugerem também um vasto campo de investigação a ser coberto. 


\section{Referências Bibliográficas}

Avia, M. D. \& Sánchez, B. M. L. (1995). Personalidad: aspectos cognitivos y sociales. Madrid: Ediciones Pirámide S. A.

Baker, R. (2000). Ataques de pânico e medo. Rio de Janeiro: Vozes.

Bazi, G. A. P. (2003). As dificuldades de aprendizagem na escrita e suas relações com traços de personalidade e emoções. Tese de Doutorado. UNICAMP.

Comte-Sponville, A. (1995). Pequeno tratado das grandes virtudes. São Paulo: Martins Fontes.

Eysenck, H. J. \& Eysenck, M. W. (1987). Personalidad y diferencias individuales. Madrid: Ediciones Pirámides.

Fiamenghi Junior, G. A. (2001). Motivos e emoções. São Paulo: Mackenzie.

Frijda, N. H. (1995). Las leyes de la emoción. Em M. D. Avia \& B. M. L Sánchez (Orgs.), Personalidad: aspectos cognitivos y sociales. Madrid: Ediciones Pirámide. S.A.

Harris, P. L. (1996). Criança e emoção. São Paulo: Martins Fontes.

Marino Junior, R. (1975). Fisiologia das emoções: introdução à neurologia do comportamento, anatomia e funções do sistema límbico. São Paulo: Sarvier.

May, R. (1975). A coragem de criar. Rio de Janeiro: Nova Fronteira.

Misrahi, R. (2001). A felicidade: ensaio sobre a alegria. Rio de Janeiro: Difel.

Pacheco, L. M. B. (2003). Comportamento de escolares: aspectos acadêmicos e psicossociais na sala de aula. Tese de Doutorado. UNICAMP.

Pacheco, L. M. B \& Sisto, F. F. (2003). Aprendizagem por interação e traços de personalidade. Psicologia Escolar e Educacional, 7(1), 69-76.

Rodrigues, M. (1976). Psicologia educacional: uma crônica do desenvolvimento humano. São Paulo: McGraw-Hill do Brasil.
Sisto, F. F. (no prelo). Escala de traços de personalidade para crianças - ETPC. São Paulo: Vetor Editora Psico-Pedagógica

Sisto, F. F. \& Bazi, G. A. P. (1999). Autopercepção de emoções. Relatório de Pesquisa, Faculdade de Educação. UNICAMP.

Sisto, T. F., Bueno, J. M. H. \& Rueda, F. J. M. (2003). Traços de personalidade na infância e distorção e integração de formas: um estudo de validade. Estudos de Psicologia, 8(1),77-84.

Sisto, F. F., Pacheco, L. M. B., Guerrero, P. V. T., \& Urquijo, S. (2001). La tensión y la ansiedad en los rasgos de personalidad: un estudio exploratorio. Acta Psiquiátrica y Psicológica de la América Latina, 47(4), 340 - 350.

Verztman, J. S. (1995). Tristeza e depressão: pensando nos problemas da vida. Rio de Janeiro: Vozes.

Viscott, D. (1982). A linguagem dos sentimentos. São Paulo: Summus. 